\title{
Status of Studies on the Ecological Disposal of the Decentralized Wastewater Treatment Technologies
}

\author{
Yanyan $\mathrm{Yu}^{1,}$, , Haibo $\mathrm{Li}^{2, \mathrm{~b}}$, Hong Wang ${ }^{1, \mathrm{c}}$, Xin Wang ${ }^{1, \mathrm{~d}}$, Xianchao $\mathrm{Ji}^{1, \mathrm{e}}$ and \\ Yulong Duan ${ }^{1, f}$ \\ ${ }^{1}$ School of environment, Shenyang University, Shenyang, 110044, China; \\ ${ }^{2}$ College of Resources and Civil Engineering, Northeast University, Shenyang 110004, China. \\ a13998178838@163.com, biamlhb@126.com, cwangh51@126.com, dwx1979@126.com, \\ jxc547365875@126.com, 'duanyulong007@163.com
}

Keywords: Decentralized wastewater treatment technology, FILTER sewage treatment system, purification tank, constructed wetlands, subsurface wastewater infiltration system.

\begin{abstract}
With the rapid development of our economy and the improve of people's living standard, domestic sewage has become an important pollution source, while rural water pollution is mainly the result from the discharge of untreated domestic sewage. Decentralized treatment of domestic sewage has become a new idea, it is widely used in some areas. In this paper, the present status and feature of rural decentralized wastewater treatment at home and abroad were reviewed, and several technologies of decentralized treatment of domestic sewage were introduced, such as FILTER sewage treatment system, purification tank, constructed wetlands, subsurface wastewater infiltration system. The technical principle, the processing effect, the advantages and disadvantages of the decentralized wastewater treatment technology were summarized, also pointed out that the decentralized wastewater treatment technology is an available approach for solving present environment protection problems and realizing sustainable development.
\end{abstract}

\section{Introduction}

With the rapid development of our economy and the rapid increase of population, the scope of water pollution is widening. The particular area which is not included in the municipal pipe network coverage and located in the suburbs or away from the town, if adopts centralized wastewater treatment method, you need to build complex drainage pipe network system, which would cost huge, and the pipeline maintenance cost is very expensive. Decentralized wastewater treatment is can save the investment, reduce the energy consumption, maintain the ecological balance and promote the implementation of the sustainable development strategy, the technology was suitable for villages and other regions without pipe network pervaded. It also can be used for sewage in on-site treatment, standards or in situ recycling [1]. This paper mainly for decentralized wastewater treatment technologies are as follows.

\section{The Concept and Characteristics of Decentralized Wastewater Treatment}

The idea of decentralized wastewater treatment is actively advocated by scientists both at home and abroad, it could achieve water cycle and balance in situ treatment and in situ reuse. In the more scattered remote areas of suburbs, rural areas and resorts, due to the restricted of economic factors and geographical position, it is more difficult to achieve the decentralized sewage collecting and centrally handle, but you can adopt decentralized wastewater treatment technology for wastewater treatment.

The cost of pipe network investment and operating in the distributed processing system will be far less than the centralized processing system, and water quality is more in line with the requirements of the water, it can further realize the sustainable development of water environment. Especially at present, our country is not the particularly economic developed area, we not only need to do our best to do recycling of resources, but also need to protect the environment, the distributed 
sewage treatment system can achieve this goal.

\section{The Study of Decentralized Wastewater Treatment at Home and Abroad}

\subsection{The "FILTER" Sewage Treatment System in Australia.}

The system is an efficient and sustainable new technology of sewage irrigation [2]. It is a sewage reuse system which combines the soil infiltration, land treatment with underground drainage tubes drainage. Through the filtered, wastewater would be collected by laying underground drainage tubes drainage system; at the same time it is equipped with sewage pump, which can regulate the emissions of treated wastewater.

"FILTER" system can not only meet the needs of crops for water and nutrients; but also can make the crop planting cost reduction. Combined with the low cost of operation management, which especially apply for the areas that has the rich land resources. However, this system is limited by crop growth cycle, and the investment cost of drainage tubes drainage is generally larger.

\subsection{Japan Purification Tank.}

Purification tank is a decentralized wastewater integrated device, which is mainly to remove the organic matter and suspended solids in the wastewater and kill bacteria, it is generally popular promoted in remote areas that are difficult to cover drainage network, and sewage cannot be included into treatment facilities to unified process. Purification tanks use dosing Effective Microorganisms bacteria into the biochemical reactions cell, using the method by strengthening microbial in the system to enhance the treatment effect [3].

Meanwhile, in order to further improve the purification tank's processing ability and the ability to resist impact load, the Japan have developed a new type of membrane separation purification tank that would be used for the depth treatment of BOD and TN [4], designed the purification tank's water balance device [5], put forward a new technology through using adsorbent to remove and recycle phosphorus [6]. Although Purification tank's processing effect is better and easy to reuse water, but its investment and operation cost is higher and processing complex, which need professional technical management personnel [7, 8].

\subsection{The Constructed Wetland Wastewater Treatment System.}

In a certain aspect ratio and bottom slope depressions, artificial wetland is as a packed bed which mixing one or several medium that concludes stone, sand, soil, cinder by a certain proportion, and on the surface of bed selectively implant high survival rate, strong water resistance, long growth cycle of aquatic plants, forming the unique ecological environment, in order to deal with wastewater [9].The constructed wetland realizes the wastewater purification mainly through matrix filtration, adsorption, precipitation, ion exchange, the absorption of plant and microbial metabolic activity. The $\mathrm{N}$ removal rate in artificial wetland is only about $50 \%$, but studies have found that [9], improving the artificial wetland's $\mathrm{BOD}$ : $\mathrm{NO}_{3}-\mathrm{N}$ ratio, the nitrogen removal rate can be increased to $80 \% \sim 90 \%$, but when the ratio rises to $2: 3$, the denitrification rate can reach a maximum. Baker's studies have shown [10], when the $C: N>5: 1$, the speed of denitrification can reach a maximum.

The artificial wetland treatment technology has some disadvantage of covering a large area, processing system instability, poor sustainability, which have been reflected that the system is largely affected by season, in summer sewage denitrification rate is as high as $90 \%$, while in winter the water quality does not meet the standard of nitrogen and phosphorus [11].

\subsection{Stabilization pond wastewater treatment technology}

Stabilization pond that also could be call Oxidation pond, pond creatures, is a biological treatment technology, which mainly relies on natural biological purification to purify the sewage. Sewage purification process in the pond is very close to water self-purification process of natural bodies, in the pond, sewage would be purified after the slow flow, storage in a long time, through microbial metabolism, making the degradation of organic pollutants in wastewater.In the water, the dissolved oxygen is the outcome of combined action of algae's photosynthesis which happens in the pond and pond surface,s reoxygenation. 
Stabilization pond remove organic matter mainly through the effect of microbial degradation, adsorption of organic compounds, organic particles sedimentation and filtration, which generally has a higher removal rate for $\mathrm{BOD}_{5}$, in the pond system, the removal rate of $\mathrm{BOD}_{5}$ is often more than $90 \%$; nitrogen would be removed by oxidation pond mainly through aquatic plant absorption, Ammonia volatilization, nitrification/denitrification; the removal of phosphorus is that the combination effect of a variety of mechanisms such as the adsorption/desorption of sediment for $\mathrm{PO}_{3}{ }^{-4}$, organic phosphorus ammoniated, the diffusion of phosphorus, the absorption of aquatic plants.

\subsection{Subsurface Wastewater Infiltration System.}

Subsurface infiltration system is one of the types of land treatment system, which is based on the principles of ecology, integrated the sewage biological treatment method of anaerobic and aerobic and formed a kind of ecological engineering of water treatment technology [12]. There are a large number of microorganisms and microscopic animals in soil which is located in $30 \sim 50 \mathrm{~cm}$ depth under the surface, under the combined effect of aerobic and anaerobic microorganisms, organic pollutants in wastewater would be adsorbed, degraded.

In the system, the removal rate of SS is up to $86 \%$, the removal efficiency of BOD more than $82 \%$, the removal rate of TN $60.3 \%$, the removal efficiency of $\mathrm{NH}_{4}{ }^{+}-\mathrm{N}$ up to $95 \%$, the removal rate of TP usually as high as $90 \%$. And there are some advantage such as the good removal effect of organic pollutants, the nitrogen and phosphorus in wastewater, low cost, small affected by temperature, without having to deal with excess sludge, the device located on the ground without damaging the landscape and so on, however, covering a large area is why its wide development would be limited.

\section{Conclusion}

Decentralized sewage ecological treatment technology not only keeps up with the international advanced environmental protection trend, but also conforms to our country trend of ecology and sustainable development in the 21 st century. Decentralized sewage ecological treatment technology is an important part of the wastewater treatment, which is suitable for the rural areas and the other regions that network is not very universal, during the selection process, we should be given priority to the less investment, low operating cost, and consider the population size, the geographical conditions, regional and regional economic conditions, etc. At present, the utilization rate of decentralized sewage treatment technology in China is still very low, which urgent need to promote and popularize.

\section{Acknowledgements}

This work has been financially supported by the Science and Technology Program of Liaoning Province (Nos. 2011229002 and 2013229012), Major Science and Technology Program for Water Pollution Control and Treatment (Nos. 2013ZX07202-007 and 2014ZX07201-009-04), Natural Science Foundation of Liaoning Province, China (2013020146), Program for New Century Excellent Talents in University (No.NECT-11-1012).

\section{References}

[1]. Li Haiming. Distributed rural sewage treatment system and practical Technology. Environmental Science \& Technology Vol. 32 (2009) No. 9, p. 177-181.

[2]. Su Donghui, Zheng Zheng, Wang Yong, et al. Discussion on treatment technology of rural domestic wastewater. Environmental Science \& Technology Vol. 28 (2005) No. 1, p. 79-80, 113.

[3]. Tian Na, Zhu Liang, Zhang Zhiyi, et al. An efficient domestic wastewater treatment facility high performance integrated purification tank. Techniques and Equipment for 
Environmental Pollution Control. Vol. 5 (2004) No. 5, p. 84-86.

[4]. Ohmori H, Yahashi T, Furukawa Y, et al. Treatment performance of newly developed johkasous with membrane separation. Wat.Sci.Tech.. Vol. 41 (2000) No. 10, p. 197-207.

[5]. Nakajima J,Tanaka R. Effectiveness of flow stabilization in small-scale wastewater treatment facilities. Wat. Sci.Tech.. Vol. 51 (2005) No. 11, p. 167-174.

[6]. Nakagawa S, Kondo T. Recovery oriented phosphorus adsorption process in decentralized advanced. Wat. Sci. Tech.. Vol. 83 (2009) No. 3, p. 328-333.

[7]. Gao Rongjing, Min Yimei. Feasibility study of Johkaso with the process of anaerobic filter bed-contact aeration treatment dispersed domestic wastewater to Tai Lake basin. Chinese Journal of Environmental Engineering. Vol. 1 (2007) No. 11, p. 1159-1163.

[8]. Min Yimei. Prospects for the Dissemination of Japanese Johkaso Technology in China. Pollution Control Technology. Vol. 16 (2003) No. 4, p. 74-75.

[9]. Yu Shaopeng, Wang Haixia, Wan Zhongjuan. Treatment Technology of Wastewater Using Constructed Wetland and Its Present Status and Future Prospects in China. Progress in Geography. Vol. 23 (2004) No. 1, p.22-29.

[10]. Xia Hanping. Mechanisms and Efficiencies on Wastewater Treatment with Constructed Wetlands. Chinese Journal of Ecology. Vol. 21 (2002) No. 4, 51-59.

[11]. Baker, L A. Design considerations and applications for wastewater treatment of high nitrate waters. Water Science and Technology. Vol. 38 (1998) No. 1, p. 389-395.

[12]. Tang Xianqiang, Li Jinzhong, Li Xueju, et al. Effect of Intermittent Artificial Aeration on Nitrogen and Phosphorus Removal in Subsurface Vertical flow Constructed. Wetlands. Environment Science. Vol. 29 (2008) No. 4, p. 897-901.

[13]. Kruzic A P. Natural treatment and on-site processes. Water Environ Res. Vol. 69 (1997) No. 4, p. 522-526. 